\title{
A rare clinic type of angiokeratoma: angiokeratoma circumscriptum naeviforme
}

\author{
Esra Arı', Seray Külcü Çakmak ${ }^{1}$, Ayşe Yılmaz Çiftçi ${ }^{2}$, Emine Tamer¹, Ferda Artüz ${ }^{1}$ \\ ${ }^{1}$ Department of Dermatology, Ankara Numune Education and Research Hospital, Ankara, Turkey, \\ ${ }^{2}$ Department of Patology, Ankara Numune Education and Research Hospital, Ankara, Turkey
}

Corresponding author: Dr. Esra Arı, E-mail: esra88ari@hotmail.com

Sir,

Angiokeratomas are verrucous, hyperkeratotic, red-black, well-demarcated papules and plaques consisting of vascular enlargement and hyperkeratosis [1]. Five different clinical variants of angiokeratoma have been identifined including angiokeratoma corporis diffusum (Fabry's disease), angiokeratoma Mibelli, angiokeratoma Fordyce, angiokeratoma circumscriptum, solitary and multiple angiokeratomas [2]. Angiokeratoma circumscriptum naeviforme, is a rare clinic type of angiokeratomas [1]. We report here a case of angiokeratoma circumscriptum naeviforme, on the lower extremity of a male patient.

A 43-year-old man presented with a red-black lineer eruption on his left leg which had been present since infancy. He gave a history of several episodes of mild bleeding from the lesions after minor trauma. There were no other local or systemic symptoms. There was no history of similar disease in his family. Dermatological examination revealed hyperkeratotic papules over dark red-black plaques on his gluteus, thigh and calf extending to the dorsum of the foot following the lines of Blaschko (Fig. 1). On the lateral part of the thigh, there were purpuric, red-black patches and on the medial part of the pretibial region there were verrucous, well-circumscribed nodules and linear plaques (Figs. 2 and 3). Both lower extremities were equal in length and diameter. No pulsation was detected by palpation of the lesions. Skin biopsy revealed hyperkeratosis and acanthosis of the stratified squamous epithelium, congestion and dilated vascular structures in papillary dermis (Fig. 4). Based on clinical and histopathological features, the diagnosis of angiokeratoma circumscriptum naeviforme was made.
The patient did not accept further investigation and therapy.

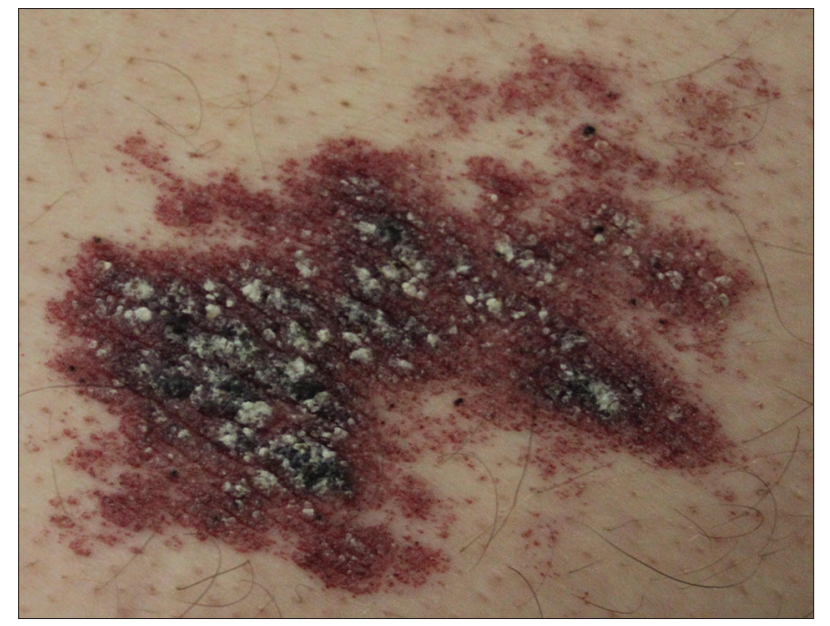

Figure 1: Hyperkeratotic papules over dark red-black plaques on the left gluteal region.

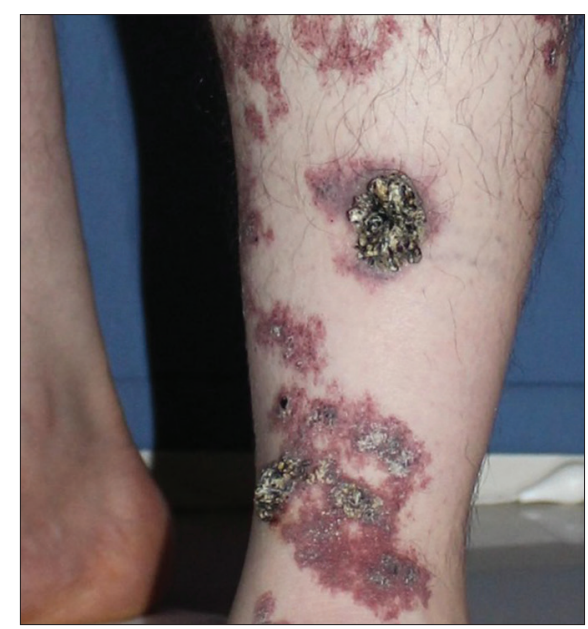

Figure 2: The verrucous nodule and hyperkeratotic patches on the pretibial region.

\footnotetext{
How to cite this article: Arı E, Çakmak SK, Çiftçi AY, Tamer E, Artüz F. A rare clinic type of angiokeratoma: angiokeratoma circumscriptum naeviforme. Our Dermatol Online. 2016;7(4):489-491.

Submission: 01.02.2016; Acceptance: 10.06.2016

DOI: 10.7241 /ourd.20164.135
} 


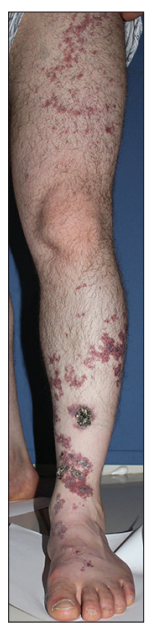

Figure 3: The lesions extending from left glutea to dorsum of the foot following the lines of Blaschko.

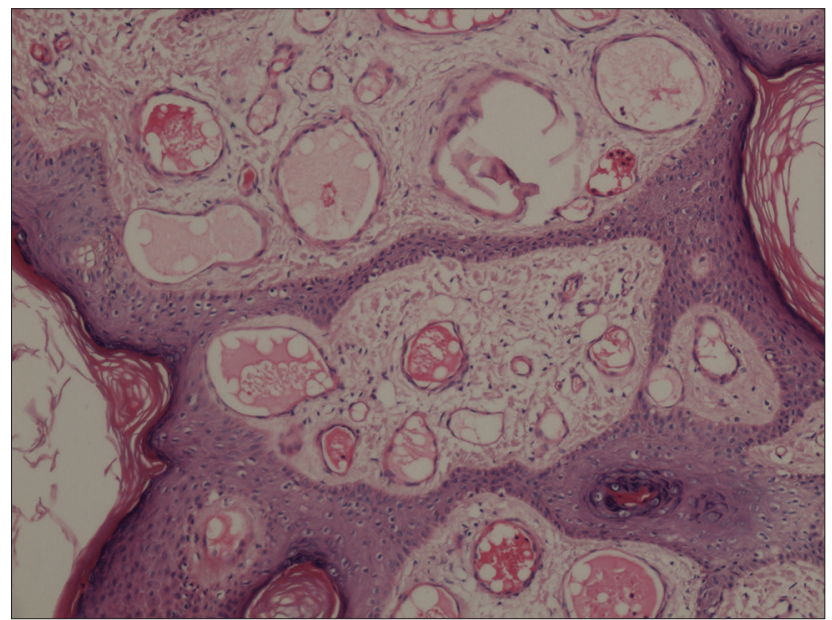

Figure 4: Hyperkeratosis and acanthosis of the stratified squamous epithelium, congestion in the papillary dermis and dilated vascular structures $(\mathrm{HE} \times 100)$.

Angiokeratoma sircumscriptum naeviforme is the rarest reported type of angiokeratomas. The lesions of angiokeratoma sircumscriptum neviforme are typically present since birth or infancy. Women are affected more commenly than men [1]. The lesions are located unilaterally on the lower site of legs or feet, but may occur on the thighs, buttocks or sometimes elsewhere. They can be varying in color from dark-red to blue-black [2]. The lesions are macular and in time can turn into warty keratotic well-circumscribed papules or nodules [3]. They tend to take a zosteriform configuration or segmental layout pattern [4]. Our patient had extensive lesions extending from left glutea to dorsum of the foot following the lines of Blaschko.

Although different in terms of appearance and layout, morphological variants of angiokeratoma are histologically similar $[5,6]$. Histologically, the overlying epidermis shows compact hyperkeratosis, acanthosis and papillamatosis and dilated capillaries are found in the papillary dermis. There is no involvement of the deep dermis and subcutaneus tissue $[2,5]$.

Although the exact reason of the formation of angiokeratomas are unknown, several causal factors, such as congenital development, pregnancy, trauma, subcutaneous hematomas, and tissue asphyxia, have all been proposed [7]. The main pathogenetic mechanism is, ectatic dilatation of capillaries in the papillary dermis with resultant secondary epidermal changes of hyperkeratosis, acanthosis [5]. Nevoid malformation of the underlying vascular network is thought to be the main cause of angiokeratoma circumscriptum neviforme [1]. The lesions may be associated with underlying vascular malformation,atrophy or hypertrophy of soft tissue and bone [6]. In our patient we could not perform imaging studies as the patient didn't accept further examination.

Our main differential diagnosis of the case was verrucous hemangioma. Verrucous hemangioma is a congenital, localized vascular malformation. Histopathologically, it is characterized by dilated capillaries and red blood cell-filled spaces extending well into the reticular dermis and subcutaneous tissue with an overlying hyperkeratotic epidermis [8].

There is no tendency of spontaneous regression in angiokeratoma sircumscriptum naeviforme. Patients may require the removal of the lesions for cosmetics reasons. Smaller lesions may be managed by diathermy, electrocautery, cryosurgery, currettage and surgery. Laser ablation [carbon dioxide or argon laser] may be used for larger lesions which are not suitable for surgery [3].

We reported here a case with congenital, linear, unilateral, verrucous plaques on the lower extremity, diagnosed as angiokeratoma circumscriptum neviforme. We report this case due to its rarity and want to emphasize that, in spite of its rarity, anigokeratoma circumscriptum should be considered in the differential diagnosis of linear verrucous lesions.

\section{REFERENCES}

1. Sardana K, Koranne RV, Sharma RC, Mahajan S. Angiokeratoma circumscriptum naeviforme: rare presentation on the neck. Australas J Dermatol. 2001;42:294-5.

2. Atherton DJ. Naevi and other developmental defects. In: Champion RH, Burton JL, Ebling FJG, eds. Textbook of 


\section{www.odermatol.com}

Dermatology, 5th edn. Oxford: Blackwell Science Ltd,1992:504.

3. del Pozo J, Fonseca E. Angiokeratoma circumscriptum naeviforme: successful treatment with carbon-dioxide laser vaporization. Dermatol Surg. 2005;31:232-6.

4. Requena L, Sangueza OP. Cutaneus vascular anomalies. PartI. Hamartomas, malformations, and dilatation of preexisting vessels. J Am Acad Dermatol. 1997;37:523-49.

5. Imperial R, Helwing EB, Angiokeratoma. A clinicopathological study. ArchDermatol. 1967;95:166-74.

6. Mittal R, Aggarwal A, Srivastava G. Angiokeratoma Circumscriptum: a case report and review of the literature. Int J Dermatol. 2005;44:1031-4.

7. Das A, Mondal AK. Angiokeratoma circumscriptum neviforme: an entity, few and far between. Indian Dermatol Online J. 2014;5:472-4.

8. Calonje E. Vascular Tumors: tumors and tumor-like conditions of blood vessels and lymphatics. In: Elder DE, Elenitsas R, Johnson BL, Murphy GF, Xu X, editors. Lever's Histopathology of Skin. 10th ed. Philadelphia: Lippincott Williams and Wilkins publishers; 2009. p. 101.

Copyright by Esra Arı, et al. This is an open access article distributed under the terms of the Creative Commons Attribution License, which permits unrestricted use, distribution, and reproduction in any medium provided the original author and source are credited.

Source of Support: Nil, Conflict of Interest: None declared. 